\title{
Assay of $\beta$-Carotene in Dietary Supplements and Fruit Juices by TLC-Densitometry
}

\author{
Małgorzata Starek • Anna Guja • Monika Dąbrowska • \\ Jan Krzek
}

Received: 14 July 2014 / Accepted: 7 October 2014 /Published online: 17 October 2014

(C) The Author(s) 2014. This article is published with open access at Springerlink.com

\begin{abstract}
$\beta$-carotene as a dietary supplement is a matter of interest to anyone who seeks to improve their skin condition or sight. Due to its antioxidative properties, carotenoids are involved in the prevention of severe conditions, such as cancer, heart disease, macular degeneration, or cataract, which makes them an object of scientific study. Thanks to its color, B-carotene is used as a food colorant, improving the appearance of foodstuff. A presented method was established for the identification and quantification of $\beta$-carotene by thin-layer chromatography with densitometric detection. As a stationary phase, TLC Aluminiumoxid $60 \mathrm{~F}_{254}$ neutral was utilized. It were activated with methanol and dried at the temperature of $60{ }^{\circ} \mathrm{C}$ for $1 \mathrm{~h}$. The development was carried out in a twin trough glass chamber saturated with a mobile phase consisting of chloroform/methanol/acetone/ammonium hydroxide (10:22:53:0.2, $v / v / v / v)$. TLC scanner was used for densitometric scanning and analysis in the absorbance mode at $450 \mathrm{~nm}$. The method was validated for specificity, linearity, precision, accuracy, limit of detection (LOD), and limit of quantification (LOQ). Presented method illustrates simple, economical, and suitable manner for routine quantitative and qualitative determination of $\beta$-carotene in dietary supplements and carrot juice.
\end{abstract}

Keywords $\beta$-carotene $\cdot$ Dietary supplements $\cdot$ Fruit juices . TLC analysis $\cdot$ Densitometric detection

M. Starek $(\square) \cdot$ A. Guja $\cdot$ M. Dąbrowska $\cdot$ J. Krzek

Department of Inorganic and Analytical Chemistry, Faculty of

Pharmacy, Jagiellonian University Medical College, 9 Medyczna

Street, 30-688 Kraków, Poland

e-mail: mstarek@cm-uj.krakow.pl

\section{Introduction}

More than 600 carotenoids have been isolated in nature and the $\beta$-carotene being the best known (Faure et al. 1999; Goodman 1984). The structure $\beta$-carotene (Fig. 1) is conjugated hydrocarbon of eight repeating isoprene units. It is a provitamin A, being converted to vitamin $\mathrm{A}$ in a human body which is necessary for the proper functioning (Goodman 1984). Deficiency of vitamin A is the main cause of premature deaths in developing countries, especially among children (Burri 1997). Although most programs of supplementation utilize vitamin $\mathrm{A}$, its high doses can induces a teratogenic effect. Therefore, it is recommended to use a rather $\beta$-carotene or eat fruits and vegetables, rich in this vitamin (De Pee et al. 1995).

$\beta$-carotene is an antioxidant, adopted in increasing quantities around the world to improve eyesight, the condition of the skin and nails, as well as to protect the body against free radicals (Burri 1997; Paiva and Russell 1999; Palozza 1998; Palozza et al. 2001). $\beta$-carotene affects the immune system, increasing the absolute number of $\mathrm{T}$ helper cells, as well as indicators of $\mathrm{T}$ cell function in animal and human models (Fryburg et al. 1995). Carotenes have also been reported to be associated with harmful events, such as at high doses for heavy smokers (Omenn et al. 1994). Therefore, its quantitative determination in food is important for the evaluation of the nutritional values, quality of fresh and processed products, and health benefits to humans.

Carotenoids are fat-soluble food components and practically insoluble in water and ethanol, but due to the high water content in the tissues from which they are harvested, an initial extraction of a water miscible solvent is usually needed (Cortes et al. 2004). The nature of the end groups of carotenoids affects their polarity, hence the different solubility in various solvents, for example, acetone, tetrahydrofuran, nhexane, pentane, petroleum ether, methanol, and their 
Fig. 1 Chemical structure of $\beta$-carotene

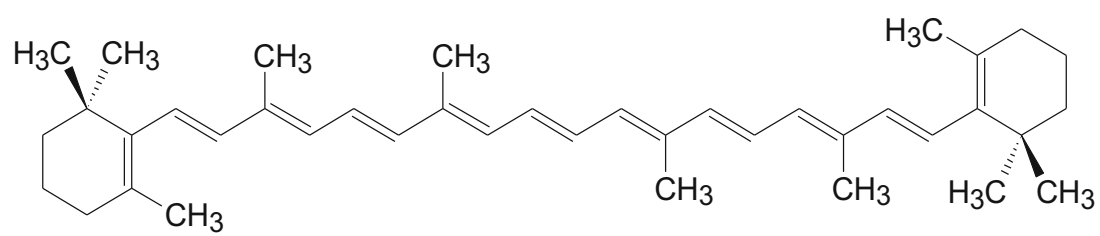

mixtures, and the need for specific methods of extraction (Taungbodhitham et al. 1998). Some of authors point to the fact that the tetrahydrofuran and diethyl ether may produce peroxides decomposing $\beta$-carotene, and therefore, it is advisable to add a butylhydroxytoluene as an antioxidant (Marsili and Callahan 1993; Quackenbush and Smallidge 1986). Different extraction procedures were used to isolate carotenoids, including simple solvent extraction, lipid phase distribution (Minguez-Mosquera and Garrido-Fernandez 1989), solid-phase extraction (Gutierrez et al. 1989), accelerated solvent extraction (Breithaupt 2004), and supercritical-fluid extraction (Gamlieli-Bonshtein et al. 2002). Extraction of carotenoids should be performed quickly, avoiding exposure to light, oxygen, high temperature, and prooxidant metals in order to minimize auto-oxidation and isomerization (Van den Berg et al. 2000).

As the reference method to the quantification of $\beta$-carotene, the spectrophotometry at 455 and $483 \mathrm{~nm}$ is recommended (European 2001). As the methods for the determination of $\beta$-carotene, spectrophotometric (Biswas et al. 2011; Schierle et al. 2002) and chromatographic methods, both in normal and reversed phase, were used (Brabcova et al. 2013; Burri et al. 1997; Guedes De Pinho et al. 2001; Hart and Scott 1995; Khachik et al. 1991; Oliver and Palou 2000; RodriguezBernaldo De Quiros and Costa 2006). The chromatographic methods with the electrochemical detection were also described (Ferruzzi et al. 1998; Murata et al. 1992). Although the presence of double conjugated bonds in the structure of $\beta$ carotene determines its electrochemical activity, however, applicable in analytical oxidation and reduction processes is limited. Ziyatdinova et al. conducted the voltammetric analysis in an aprotic organic medium adding various surfactants (Ziyatdinova et al. 2012).

Thin-layer chromatography (TLC) was found to have the potential to be the first choice for analysis of carotenoids in vegetable and biological samples (Murkovic and Zeb 2010). TLC is still a widely used technique due to its reliability, simplicity, reproducibility, and speed in analysis of pharmaceuticals, botanicals, foodstuff, environmental, and clinical samples (Renger et al. 2011). Direct applications of suspensions, dirty, or turbid samples also are possible (Dorni et al. 2007). Additionally, composition of used mobile phase is not very important for detection as it is observed in HPLC. For the determination of $\beta$-carotene in fruits, musts, wines, snails, leeches, and fancy carp, the TLC analysis was referenced with the use of eluents in reversed phase with mobile phases composed of petroleum ether or diethyl ether (Arthur et al. 2006; Bundit et al. 2008; Evans et al., 2004; Ligor and Buszewski 2007; Martin et al. 2005). Sherma and Fried described the qualitative analysis of $\beta$-carotene by TLC from an extract of spinach (Sherma and Fried 2004). A mobile phase containing the petroleum ether and various solvents in a different ratio has been used for TLC analysis of $\beta$-carotene, oxidized carotenoids, vitamin $\mathrm{A}$, and carotenoid mixtures (Martin et al. 2005; Minguez-Mosquera et al. 1992; Arthur and Sherma 2007). Although several techniques have been used for analysis of carotenoids form various sources, literature describing the analysis of carotenoids by TLC in detail is limited (Jarusiewicz et al. 2006; Sherma 2000). In available literature, no papers were found describing determination of $\beta$-carotene in dietary supplements and fruit juices by TLC with densitometric detection and using a mobile phase without ether which is consequently eliminated from routine analysis because of its toxicity.

The purpose of this research was to present a rapid, precision, and accurate analytical method for the determination of $\beta$-carotene in dietary supplements and fruit juices based on a simple extraction method, as well as a TLC-densitometry technique. The presented method employs a TLCAluminiumoxid layer, automated band-wise sample application, densitometric scanning of the yellow $\beta$-carotene standard, and sample bands.

\section{Materials and Methods}

\section{Materials and Chemicals}

The standard of $\beta$-carotene was purchased from SIGMA (cat no C9750). Dietary supplements and juices were used: BetaKaroten optimal, $6 \mathrm{mg} /$ capsule (Alpepharma, Jelenia Góra, Poland); BetaSolar, $15 \mathrm{mg} /$ capsule (Olimp Lab., Dębica, Poland); $\beta$-carotene plus, $6 \mathrm{mg} /$ tablet (Aflofarm, Ksawerów, Polska); BetaSunBio, $6 \mathrm{mg} /$ tablet (Sun-Farm, Kołbiel, Poland); BelissaSun, $10 \mathrm{mg} /$ tablet (Aflofarm, Ksawerów, Polska); Natus carote juice (Natus, Poland); Kubuś juice, composition: purees and juice from Mazurska carrot, bananas, and apples, water, glucose-fructose syrup, citric acid, vitamin C (MWS, Poland); Dizzy juice, composition: carrot puree, water, bananas puree, apple puree, sugar, citric acid, vitamin $C$; juice containing no less than $2.5 \mathrm{mg}$ of $\beta$-carotene (Lidl Stiftung\&Co.KG). Methanol, glacial acetic 
acid $99.5 \%$, n-hexane, cyclohexane, toluene, ammonium $35.04 \mathrm{~g} / \mathrm{mol}$ were purchased from Chempur (Piekary Ślaskie, Poland). Acetone, isopropanol, ethyl acetate, chloroform, butanol, dichloromethane were purchased from POCH, Gliwice. All used reagents were of analytical grade.

\section{Preparation of Standard Solution}

Ten milligrams of $\beta$-carotene standard were weighed and transferred to a $5-\mathrm{mL}$ volumetric flask. Ethyl acetate was added. The flask was shaken, and volume was made up to the mark to give a $0.2 \%(w / v)$ solution.

\section{Sample Preparation}

Five capsules or tablets were weighed and powder was collected from the shell. The powder equivalent to $5-\mathrm{mg} \beta$ carotene was accurately weighed and transferred to a volumetric flask. Ethyl acetate was added and shaken for $10 \mathrm{~min}$. Next, the volume was made up to the mark with ethyl acetate. The above solution was filtered through Whatman filter paper $(0.45 \mu \mathrm{m})$; this would give a $0.2 \%(w / v)$ solution.

Forty milliliter of juice and $80 \mathrm{~mL}$ of chloroform were dispensed to the separatory funnel of capacity $200 \mathrm{~mL}$. Contents were shaken for $15 \mathrm{~min}$, left to the phase separation, and next, the chloroform layer was separated from the aqueous layer. The extraction process was repeated three times. The collected chloroform layer was evaporated at $30^{\circ} \mathrm{C}$ to a volume of $50 \mathrm{~mL}$ and used for the study.

\section{TLC Conditions}

TLC analysis was performed on the precoated TLC Aluminiumoxid $60 \mathrm{~F}_{254}$ neutral (typ E) (Merck, Darmstadt, Germany) $10 \times 10$-cm plates, cut from $20 \times 20 \mathrm{~cm}$. Before using, the plates were activated with methanol. Next, they were dried in the incubator at temperature $60^{\circ} \mathrm{C}$ by $1 \mathrm{~h}$. The samples in $10-\mu \mathrm{L}$ volumes of appropriate solution were applied on thus prepared stationary phase with Linomat V applicator (CAMAG, Muttenz, Switzerland), as $10 \mathrm{~mm}$ width bands, with distance of $10 \mathrm{~mm}$ from the plate bottom, $10 \mathrm{~mm}$ from the edge, and 8-mm distance between the bands. The mobile phase consisted of chloroform/methanol/acetone/ ammonia $25 \%(10: 22: 53: 0.2, v / v / v / v)$. Chromatograms were developed in a room temperature on the distance of $9 \mathrm{~cm}$ within about $40 \mathrm{~min}$ in glass chromatographic chambers $(17.5 \times 16 \times 8.2 \mathrm{~cm}$ in size; Sigma-Aldrich $)$, saturated with vapor of mobile phase for $15 \mathrm{~min}$. After drying at the air in a dark place, plates were scanned and obtained spots were recorded by using TLC Scanner 3 (CAMAG, Muttenz, Switzerland) with Cats 1.3 .4 software at $450 \mathrm{~nm}$.

Retardation factor $\left(R_{f}\right)$ for the $\beta$-carotene (standard and samples) was designated. For the quantitative analysis of $\beta$ - carotene, the values of the peak area obtained on the densitograms were recorded.

\section{Method Validation}

The developed TLC method was validated as per International Conference on Harmonisation (ICH) guidelines (ICH 2000) by specificity, linearity, limit of detection (LOD), limit of quantification (LOQ), precision, accuracy, robustness, and ruggedness.

\section{Specificity}

The specificity of the method was confirmed by analyzing the standard substance and the extract. The band for $\beta$-carotene in the sample was confirmed by comparing the $R_{f}$ values and absorption spectra of the band with that of the standard. The peak purity of the $\beta$-carotene was assessed by comparing the spectra at three different levels, viz., peak start (S), peak apex (M), and peak end (E) positions of the band.

\section{Linearity}

The linearity was checked for six solutions in a range from 0.5 to $9.5 \mu \mathrm{g}$ per band. Results of calibration curve parameters were estimated by Statistica software.

\section{Limit of Detection and Limit of Quantitation}

The LOD and LOQ were establish based on standard deviation of intercept $\left(\mathrm{S}_{\mathrm{b}}\right)$ and slope of a straight line (a), obtained for the calibration curve. Following formulations, $\mathrm{LOD}=$ $3.3 \mathrm{~S}_{\mathrm{b}} / \mathrm{a}$ and $\mathrm{LOQ}=10 \mathrm{~S}_{\mathrm{b}} / \mathrm{a}$ were applied for the estimation.

\section{Precision}

Repeatability of the sample application and measurement of peak area were carried out using nine determinants (3 concentrations $/ 3$ replicates) covering the specified range for the procedure $(1,5$, and $9 \mu \mathrm{g}$ per band of $\beta$-carotene) and was expressed in terms of relative standard deviation (\% RSD). Acceptance criteria for a procedure's repeatability or intermediate precision are based on the intended use of the analytical method. A repeatability showing a random standard deviation of $\leq 1.0 \%$ may be acceptable for assaying substance in the formulations with a given specification range. Indirect precision was estimated in another day and by different analyst in analogical way.

\section{Accuracy}

To investigate the accuracy in sample preparation (i.e., extraction efficiency), a spiked solution by adding known amounts 
of related substances into a sample matrix was prepared. Thereafter, responses of the spike solutions and the standard solutions were taken to assess the recovery from the sample preparation. Recovery studies were carried out by addition of standard $\beta$-carotene to the sample at three different concentration levels $(80,100$, and $120 \%)$, taking into consideration percentage purity of added bulk preparations samples. The experiment was conducted three times.

\section{Ruggedness}

$\beta$-carotene in solution of concentration $2 \mu \mathrm{g}$ per band was prepared and analyzed on day 0 and after 12 and $24 \mathrm{~h}$. Data were treated for $\%$ RSD to assess the ruggedness of the method.

\section{Robustness}

By introducing small changes in the mobile phase volume, duration of mobile phase saturation, and activation of prewashed TLC plates with methanol, the effects on the obtained results were examined. Robustness of the method was done in triplicate at a concentration level of $2 \mu \mathrm{g}$ per band for $\beta$-carotene, and the \% RSD values were calculated.

Determination of $\beta$-Carotene in Dietary Supplements and Fruit Juices

Determination of $\beta$-carotene was carried out according to the procedure describing above in five dietary supplements and three fruit juices. For each preparation and juice, ten measurements were performed. Estimation of $\beta$-carotene content was done by comparing peak areas for standard solutions with peak areas for studied solutions. For each series of results, the statistical analysis was done.

\section{Results and Discussion}

Here in the paper, the conditions for the identification and determination of $\beta$-carotene in dietary supplements and fruit juices were determined and presented. The assay was provided using TLC technique with densitometric detection.

\section{Optimization of TLC Conditions}

In the first stage of studies, conditions for separation of $\beta$ carotene were established. For the selection of the stationary phase, various plates were tested, such as TLC Cellulose F, TLC Kieselgel $60 \mathrm{WF}_{254} \mathrm{~S}$, Silica gel $60 \mathrm{~F}_{254}$, TLC Polyamide ${ }_{11} \mathrm{~F}_{254}$, TLC Aluminiumoxid $60 \mathrm{~F}_{254}$ neutral (typ E) (Merck,
Darmstadt, Germany). On these plates, $10-\mu \mathrm{L} 0.02 \%$ standard solution and selected supplements were applied as a band of 1-cm wide by means of an automatic sampler. The mobile phase composition was established by checking the solvent mixtures of varying qualitatively and quantitatively compositions, based on the eluotropic series. The following testing mobile phases were tried: toluene/ethyl acetate/glacial acetic acid $(15: 4: 1, v / v / v)$, cyclohexane/ethyl acetate $(7: 3, v / v)$, acetone/n-hexane $(3: 7, v / v)$, n-hexane/isopropanol/methanol (10:0.2:0.02, v/v/v), chloroform/acetone/toluene (12:5:2, $v / v /$ $v)$, ethanol/isopropanol/glacial acetic acid/water (4:4:1:3, $v / v /$ $v / v)$, n-hexane/acetone $(4: 1, v / v)$, chloroform/acetone/toluene $(12: 5: 2, v / v / v)$, acetone/n-hexane/methanol $(4: 1: 1, v / v / v)$, butanol/glacial acetic acid/water $(12: 3: 5, v / v / v)$, ethanol/water/glacial acetic acid $(10: 2: 0.1, v / v / v)$, chloroform/methanol/ acetone/ammonia $25 \%$ (10:22:53:0.05, $v / v / v / v)$, chloroform/ methanol/acetone/ammonia $25 \%(10: 22: 53: 0.2, v / v / v / v)$, chloroform/methanol/acetone/butylamine (10:22:53:1, $v / v / v /$ $v)$, chloroform/methanol/ammonia $25 \%(10: 22: 0.2, v / v / v)$, chloroform/methanol/butylamine $(10: 22: 10, v / v / v)$. The plates were developed on the way of $9 \mathrm{~cm}$ at room temperature and then air-dried. The obtained chromatograms were analyzed in terms of color of the spots and background. The acquired densitograms were rated in terms of separate and shape of the peaks. Finally, TLC Aluminiumoxid $60 \mathrm{~F}_{254}$ neutral (typ E) plates as the stationary phase were found, after initial purification by prewash with methanol and activation in the oven (BMT, Brno, Czech Republic) for $1 \mathrm{~h}$ at $60{ }^{\circ} \mathrm{C}$. Furthermore, chloroform/methanol/acetone/ammonia $25 \%$ (10:22:53:0.2, $v / v / v / v)$ was found to be satisfactory and gave good separation for $\beta$-carotene without any interference from excipients (Fig. 2). The appointed $R_{f}$ value for $\beta$-carotene was 0.90 . The obtained chromatograms were subjected to densitometric analysis by recording absorption spectra within the wavelength range of $200-600 \mathrm{~nm}$. The scanning spectra of $\beta$ carotene revealed that at $450 \mathrm{~nm}$, it possesses significant absorbance (Fig. 3). So, it was selected as detection wavelength. Application of the described above conditions has allowed to obtain a compact spots and well-shaped peaks, allowing to perform the quantitative determination of $\beta$ carotene.

\section{Extraction of $\beta$-Carotene}

In order to optimize the extraction of $\beta$-carotene, the following solvents were tested: methanol, ethyl acetate, chloroform, dichloromethane, and hexane, in terms of the solubility of the $\beta$-carotene substances. Finally, ethyl acetate was chosen for the extraction of $\beta$-carotene from dietary supplements and chloroform for the extraction from the juices. In these conditions, the best recovery of the substance was achieved. 

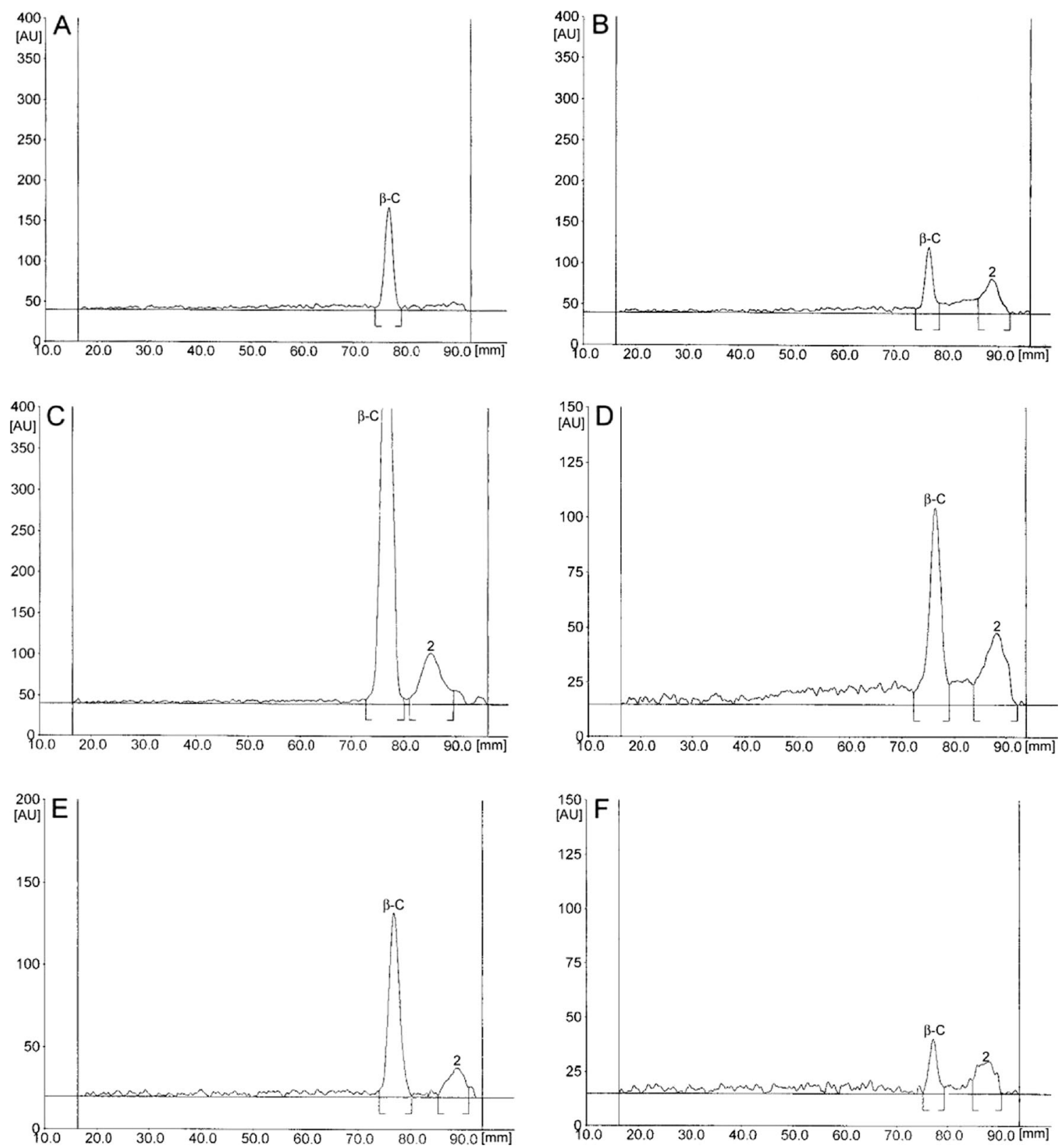

Fig. 2 An example of densitograms obtained for preparations: BetaSunBio (a), BetaSolar (b), Betacaroten plus (c), Natus juice (d), Kubuś juice (e), and Dizzy juice (f) under described conditions ( $\beta-\mathrm{C}-\beta$-carotene; 2 - additional peaks)

\section{Validation of the Method}

The presented method was validated for assay of $\beta$-carotene in accordance with ICH guidelines. The specificity of the method was confirmed by analyzing the standard compound and the extracts. The band for $\beta$-carotene in the sample was confirmed by comparing the $R_{f}$ values and spectra of the band with those of the standard. The peak purity of $\beta$-carotene was assessed by comparing the absorption spectra at three different levels, viz., peak start (S), peak apex (M), and peak end (E) positions of the band. The mobile phase used enabled good resolution for $\beta$-carotene at $R_{f} 0.90$ and wavelength $450 \mathrm{~nm}$. Chromatograms obtained from standard and sample solutions are shown in Fig. 2.

Amounts of standard solutions equivalent to $0.76-9.14 \mu \mathrm{g}$ of $\beta$-carotene per band were applied to the plate. The plate was developed and scanned. The data of peak areas plotted against the corresponding concentrations were treated by least square regression analysis. The slope, intercept, and correlation coefficient were also determined. Over the studied calibration range, the correlation coefficient for $\beta$-carotene was found to be $r=0.9990$. The regression parameters are shown in Table 1. 

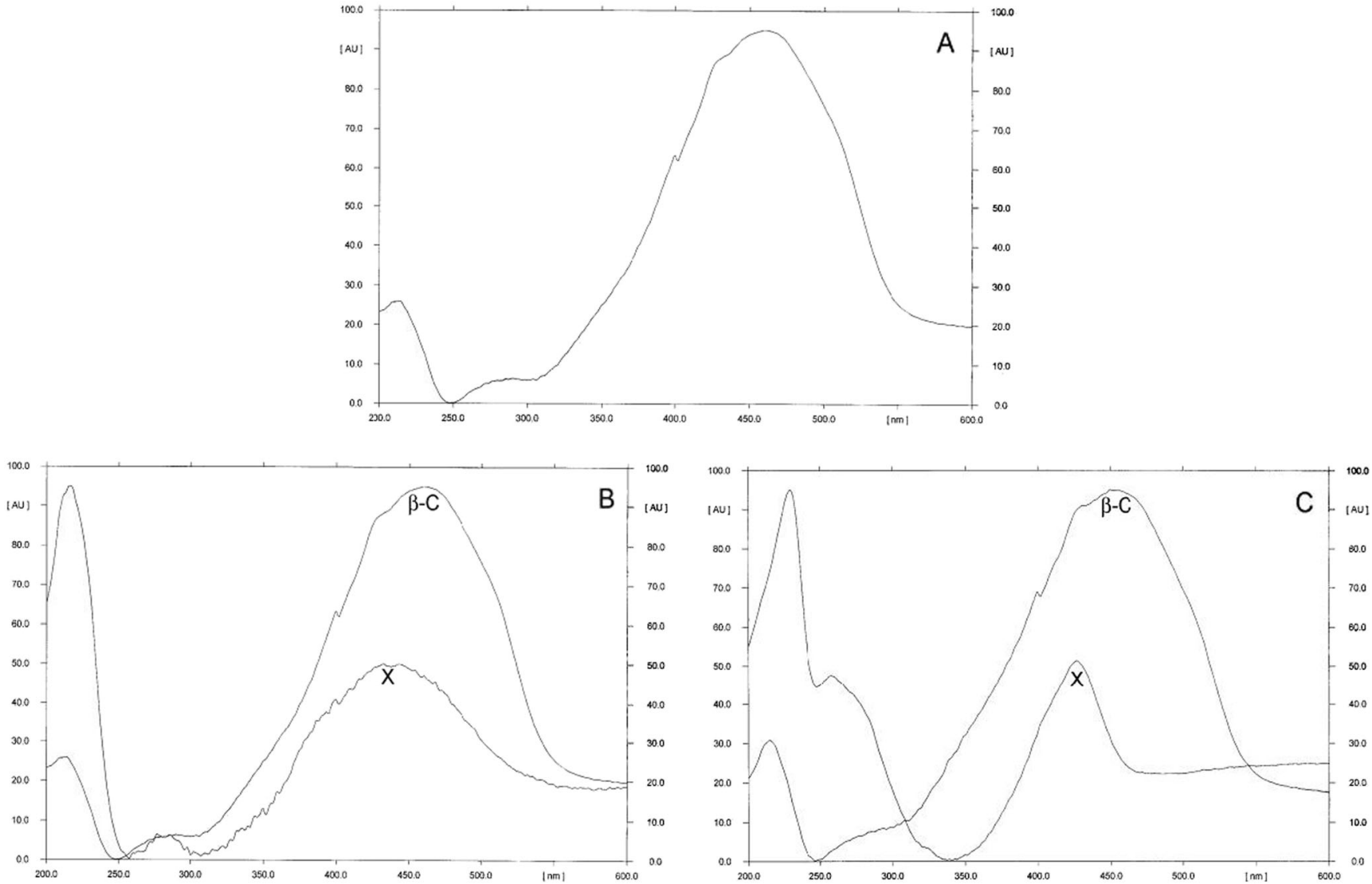

Fig. 3 An absorption spectrum for $\beta$-carotene standard (a). An absorption spectra for Betacaroten plus (b) and Kubuś juice (c) recorded for each two registered peaks (presented on Fig. $2 ; \beta-\mathrm{C}-\beta$-carotene; $\mathrm{X}$-additional substance). All spectra were obtained directly from the chromatograms

The sensitivity of measurement of $\beta$-carotene using the proposed method was estimated as LOQ, and the lowest

Table 1 The results of the method validation

\begin{tabular}{ll}
\hline Parameter & Result \\
\hline $\begin{array}{c}\text { Linearity } \\
(\mu \mathrm{g} / \mathrm{band})\end{array}$ & $0.76-9.14 P=2214.5 \mathrm{c}+650.2 ; r=0.9990$ \\
LOD $(\mathrm{mg} / \mathrm{L})$ & 103 \\
LOQ $(\mathrm{mg} / \mathrm{L})$ & 313 \\
Intra-day & $10719.7 ; 10753.7 ; 10894.2 ; 10744.5 ; 10858.6 ; 10841.3 ;$ \\
precision & $10910.2 ; 10890.5 ; 10765.1 x_{m}=10819.76 ; S=73.93 ;$ \\
& $S_{x m}=24.64 ; \mathrm{RSD}=0.68 \%$ \\
Inter-day & $10763.8 ; 10936.5 ; 10712.6 ; 10716.9 ; 10957.1 ; 10857.5 ;$ \\
precision & $10857.5 ; 10912.9 ; 10916.4 x_{m}=10847.91 ; S=94.48 ;$ \\
& $S_{x m}=31.49 ; \mathrm{RSD}=0.87 \%$ \\
Accuracy & Level $80 \%: 100.79 ; 99.85 ; 101.04 ; 100.06 ; 99.88 ;$ \\
& $99.94 x_{m}=100.26 ; S=0.52 ; S_{x m}=0.21 ; \mathrm{RSD}=0.52 \%$ \\
& $l e v e l 100 \%: 100,11 ; 99,02 ; 101,03 ; 99,97 ; 100,77 ;$ \\
& 100,$57 ; x_{m}=100.25 ; \mathrm{S}=0.72 ; S_{x m}=0.29 ; \mathrm{RSD}=$ \\
& $0.72 \%$ level $120 \%: 99.96 ; 99.51 ; 99.80 ; 100.17 ;$ \\
& $99.33 ; 98.74 x_{m}=99.59 ; S=0.51 S_{x m}=0.21 ; \mathrm{RSD}=$ \\
& $0.51 \%$
\end{tabular}

$P$ peak area, $c$ concentration, $r$ correlation coefficient, $x_{m}$ arithmetic mean, $S$ standard deviation, $S_{x m}$ standard deviation of the mean, $R S D$ relative standard deviation $(\%)$ concentration detected under these chromatographic conditions as LOD. The obtained LOD and LOQ for $\beta$-carotene were 103 and $313 \mathrm{mg}$ per L, respectively.

The precision of the method, as intra-day variation (\% RSD), was determined by analysis of standard solutions in the range of 1-9 $\mu \mathrm{g}$ per band three times on the same day. Inter-day precision (\% RSD) was assessed by analysis of the same solution on three different days over a period of 1 day. The relative standard deviation values for both intra- and interday precision values were $\leq 1.0 \%$. The results from study of precision are shown in Table 1.

The accuracy of the method was determined by analysis of standard additions at three concentration levels. The obtained results of accuracy of $\beta$-carotene in formulation are $<1 \%$ of RSD, and they are given in Table 1. Obtained results indicated that the proposed method is accurate.

By introducing small changes in the mobile phase volume, duration of mobile phase saturation, and activation of prewashed TLC plates with methanol, the effects on the results were examined.

A $\beta$-carotene solution was prepared and analyzed on day 0 and after 12 and $24 \mathrm{~h}$. Data were treated for \% RSD to assess ruggedness of the method. The relative standard deviation of the results obtained by different analysts was $<1.0 \%$. Thus, 
Table 2 Statistical evaluation of $\beta$-carotene content in tested dietary supplements and juices with the statistical evaluation

\begin{tabular}{|c|c|c|c|}
\hline Preparation & $\begin{array}{l}\text { Declared content } \\
(\mathrm{mg})\end{array}$ & Determined content (mg) & Statistical data $(n=10)$ \\
\hline $\begin{array}{l}\text { BetaKaroten } \\
\text { optimal }\end{array}$ & $3.6 \mathrm{mg} /$ capsule & $0.18,0.18,0.18,0.18,0.17,0.18,0.18,0.18,0.18,0.18$ & $x_{m}=0.1790 \mathrm{~S}=0.0032 ; S_{x m}=0.0010 \mathrm{RSD}=1.77 \%$ \\
\hline Betasolar & $15 \mathrm{mg} / \mathrm{capsule}$ & $0.88,0.89,0.89,0.90,0.91,0.89,0.90,0.91,0.90,0.88$ & $x_{m}=0.8950 S=0.0108 ; S_{x m}=0.0034 \mathrm{RSD}=1.21 \%$ \\
\hline BetaSunBio & $6 \mathrm{mg} /$ capsule & $1.65,1.69,1.69,1.65,1.65,1.68,1.64,1.64,1.66,1.64$ & $x_{m}=1.6620 S=0.0210 ; S_{x m}=0.0066 \mathrm{RSD}=1.26 \%$ \\
\hline BelissaSun & $10 \mathrm{mg} /$ tablet & $\begin{array}{l}10.42,10.37,10.26,10.21,10.36,10.42,10.24,10.35 \\
10.28,10.26\end{array}$ & $x_{m}=10.3170 S=0.0762 ; S_{x m}=0.0241 \mathrm{RSD}=0.74 \%$ \\
\hline Betacaroten plus & $10 \mathrm{mg} /$ tablet & $\begin{array}{l}15.69,15.84,15.85,15.78,15.36,15.86,15.86,15.56 \\
\quad 15.50,15.94\end{array}$ & $x_{m}=15.7240 S=0.1906 ; S_{x m}=0.0603 \mathrm{RSD}=1.21 \%$ \\
\hline $\begin{array}{l}\text { Natus fresh } \\
\text { carrot juice }\end{array}$ & $-/ 100 \mathrm{~mL}$ & $\begin{array}{l}19.53,19.75,19.93,20.21,20.11,20.20,19.83,19.92 \\
\quad 20.07,19.78\end{array}$ & $x_{m}=19.9330 S=0.2181 ; S_{x m}=0.0690 \mathrm{RSD}=1.09 \%$ \\
\hline Kubuś juice & $-/ 100 \mathrm{~mL}$ & $\begin{array}{l}12.03,12.16,12.23,11.72,11.86,12.10,11.96,11.77 \\
12.08,11.95\end{array}$ & $x_{m}=11.9860 S=0.1663 ; S_{x m}=0.0526 \mathrm{RSD}=1.39 \%$ \\
\hline Dizzy juice & $>2.5 \mathrm{mg} / 100 \mathrm{~mL}$ & $5.23,5.13,5.18,5.13,5.13,5.14,5.10,5.11,5.17,5.06$ & $x_{m}=5.1380 S=0.0469 ; S_{x m}=0.0148 \mathrm{RSD}=0.91 \%$ \\
\hline
\end{tabular}

“_" no data, $x_{m}$ arithmetic mean, $S$ standard deviation, $S_{x m}$ standard deviation of the mean, $R S D$ relative standard deviation (\%)

statistical analysis showed no significant difference between results obtained by applying the analytical conditions established for the method and those obtained in experiments in which some of the conditions were varied slightly.

\section{Determination of $\beta$-Carotene in Dietary Supplements and Fruit Juices}

Usefulness of the developed method for routine studies was proved during determination of $\beta$-carotene in studied formulations. The five tested dietary supplements confirmed the presence of the active compound (Table 2) but not always in an amount declared by the manufacturer.

Relative standard deviation obtained from determination of $\beta$-carotene confirmed insignificant differences between results obtained from BelissaSun dietary supplement and declaration of contents. In some of the preparations, deficiency of $\beta$-carotene was observed (BetaSolar, BetaKaroten optimal, BetaSunBio), and in $\beta$-carotene plus the excess of this component was observed. Thus, this results indicate a possible decomposition of $\beta$-carotene during storage time in out-data supplements. $\beta$-carotene is commonly used in food processing as a coloring additive. A high $\beta$-carotene content in the formulation $\beta$-carotene plus, relative to the declared value, may derive from the presence of coloring additives of a similar chemical structure to the determined substance. Additionally, $\beta$-carotene content in the juices was determined in the range of 5.1380-19.9330 mg of the substance per $100 \mathrm{~mL}$ of juice with a good RSD value $<1.5 \%$. In the case of three supplement formulations, on the recorded chromatograms, only one peak of $\beta$-carotene was obtained, and no matrix component was detected by densitometric detector. While analyzing two dietary supplements (BetaSolar, $\beta$-carotene plus) and all juices, there were additional spots in chromatograms. These spots differ in position (various $R_{f}$ values), but their absorption spectra were related (Fig. 3), thus suggesting that additional peaks may have a similar chemical structure. $\beta$-carotene formed a symmetrical peak, clearly separated from the additional peaks, which confirmed parameters calculated for registered peaks, $R_{s}$ (resolution factor) and $\alpha$ (separation factor) (Table 3).

As a result of presented study, the conditions were established to make determination of $\beta$-carotene in commonly available dietary supplements and fruit juices. The analyses of $\beta$-carotene were carried out by employing a simple and economical TLC-densitometry procedure that, with the advances in densitometric instrumentation, provides new opportunities for dietary supplements and juice quality control.

\section{Conclusions}

A sensitive, rugged, and reproducible TLC method was developed and validated according to the ICH guidelines, for the subsequent separation and detection of $\beta$-carotene. Validation experiments provided proof that TLC analytical method is linear in the proposed working range as well as accurate,

Table 3 Results presenting resolution of $\beta$-carotene and additional peaks on TLC Aluminiumoxid $60 \mathrm{~F}_{254}$ plates

\begin{tabular}{llll}
\hline Preparation & Substance & $R_{s}$ & $\alpha$ \\
\hline BetaSolar & $\beta$-carotene - add peak $\left(R_{f}=0.87\right)$ & 0.66 & 2.33 \\
Betacaroten plus & $\beta$-carotene - add peak $\left(R_{f}=0.83\right)$ & 0.29 & 1.75 \\
Natus juice & $\beta$-carotene - add peak $\left(R_{f}=0.86\right)$ & 0.40 & 2.19 \\
Kubus juice & $\beta$-carotene - add peak $\left(R_{f}=0.88\right)$ & 0.55 & 2.50 \\
Dizzy juice & $\beta$-carotene-add peak $\left(R_{f}=0.86\right)$ & 0.60 & 2.19 \\
\hline
\end{tabular}

$R_{S}$ resolution factor, $R_{S}=2$ (distance between the centers of two adjacent spots)/(sum of the widths of the two spots in the direction of development), $\alpha$ separation factor, $\alpha=\left[\left(1 / R_{f 1}\right)-1\right] /\left[\left(1 / R_{f 2}\right)-1\right]$ 
precise, and specific, being able to separate the main compound from the matrix. The proposed mobile phase of TLC effectively resolves $\beta$-carotene. The method can be used for qualitative as well as quantitative determination of $\beta$-carotene in dietary supplements and fruit juices and for purity estimation. TLC fingerprints were obtained for all the extracts giving reliable indication of the same identity. This method can be also used in routine analysis of food and pharmaceuticals containing $\beta$-carotene, especially due to the speed of analysis and reduction of the consumption of organic solvents.

Conflict of Interest Małgorzata Starek declared that she has no conflict of interest. Anna Guja declared that she has no conflict of interest. Monika Dabrowska declared that she has no conflict of interest. Jan Krzek declared that he has no conflict of interest. This article does not contain any studies with human or animal subjects.

Open Access This article is distributed under the terms of the Creative Commons Attribution License which permits any use, distribution, and reproduction in any medium, provided the original author(s) and the source are credited.

\section{References}

Arthur B, Fried B, Sherma J (2006) Effect of estivation of lutein and bcarotene concentrations in Biomphalaria glabrata (NMRI Strain) and Helisoma trivolvis (Colorado Strain) Snails as determined by quantitative high performance reversed phase thin layer chromatography. J Liq Chromatogr Relat Technol 29:2159-2165

Arthur B, Sherma J (2007) Quantification of beta-carotene in a dietary supplement by reversed phase high performance thin layer chromatography using a chrome image flatbed scanner in the visible mode. Acta Univer Cibin F Chemia 10:3-9

Biswas AK, Sahoo I, Chatli MK (2011) A simple UV-vis spectrophotometric method for determination of $\beta$-carotene content in raw carrot, sweet potato and supplemented chicken meat nuggets. LWT Food Sci Technol 44:1809-1813

Brabcova I, Hlavackova M, Satinsky D, Solich P (2013) A rapid HPLC column switching method for sample preparation and determination of $\beta$-carotene in food supplements. Food Chem 141:1433-1437

Breithaupt DE (2004) Simultaneous HPLC determination of carotenoids used as food coloring additives: applicability of accelerated solvent extraction. Food Chem 86:449-456

Bundit Y, Orapint J, Nontavit A, Prathak T (2008) Validated TLCdensitometric analysis for determination of carotenoids in fancy carp (Cyprinus carpio) serum and the application for pharmacokinetic parameter assessment Songklanakarin. J Sci Technol 6:693-700

Burri BJ (1997) Beta-carotene and human health: a review of current research. Nutr Res 17:547-580

Burri BT, Neidlinger TR, Lo AO, Kwan C, Wong MR (1997) Supercritical fluid extraction and reversed-phase liquid chromatography methods for vitamin $A$ and $\beta$-carotene heterogeneous distribution of vitamin A in the liver. J Chromatogr A 762:201-206

Cortes C, Esteve MJ, Frigola A, Torregrosa F (2004) Identification and quantification of carotenoids including geometrical isomers in fruit and vegetable juices by liquid chromatography with ultravioletdiode array detection. J Agric Food Chem 52:2203-2212
De Pee S, West CE, Hautvast JGAJ, Muhilal Karyadi D, West CE (1995) Lack of improvement in vitamin A status with increased consumption of dark-green leafy vegetables. Lancet 346:75-81

Dorni AIC, Vidyalakshmi KS, Vasanthi RH, Rajamanickam GV (2007) HPTLC method for the quantification of plumbagin in three Plumbago species. Res J Phytochem 1:46-51

European Pharmacopoeia (2001) Strasbourg, France: Council of Europe

Evans RT, Fried B, Sherma J (2004) Effects of diet and larval trematode parasitism on lutein a b-carotene concentrations in planorbid snails as determined by quantitative high performance reversed phase thin layer chromatography. Comp Biochem Physiol B Biochem Mol Biol 137:179-186

Faure H, Fayol V, Galabert C, Grolier P, Le Moel G, Steghens JP, Van Kappel A, Nabert F (1999) Carotenoids: 1. Metabolism and physiology. Ann Biol Clin 57:169-183

Ferruzzi MG, Sauder LC, Rock CL, Schwartz SJ (1998) Carotenoid determination in biological microsamples using liquid chromatography with a coulometric electrochemical array detector. Anal Biochem 256:74-81

Fryburg DA, Mark RJ, Griffith BP, Askenase PW, Patterson TF (1995) The effect of supplemental beta-carotene on immunologic indices in patients with AIDS: a pilot study. Yale J Biol Med 68:19-23

Gamlieli-Bonshtein I, Korin E, Cohen S (2002) Selective separation of cis-trans geometrical isomers of $\beta$-carotene via $\mathrm{CO}_{2}$ supercritical fluid extraction. Biotechnol Bioeng 80:169-174

Goodman DS (1984) Provitamin A function of carotenoids: the conversion of $\beta$-carotene into vitamin A. N Engl J Med 310:1023-1031

Guedes De Pinho P, Silva Ferreira AC, Mendez Pinto M, Gomez Benitez J, Hogg TA (2001) Determination of carotenoid profiles in grapes, musts, and fortified wines from douro varieties of Vitis vinifera. $\mathrm{N}$ Engl J Med 49:5484-5488

Gutierrez F, Albi MA, Palma R, Rios JL, Olb JM (1989) Bitter taste of virgin olive oil: correlation of sensory evaluation and instrumental HPLC analysis. J Food Sci 54:68-70

Hart DJ, Scott KJ (1995) Development and evaluation of an HPLC method for the analysis of carotenoids in food, and the measurement of carotenoid content of vegetables and fruits commonly consumed in UK. Food Chem 54:101-111

ICH (2000) Text on Validation of Analytical Procedures: Methodology, International conference on Harmonization of Technical Requirements for Registration of Pharmaceutical for Human Use. Geneva, Switzerland

Jarusiewicz A, Fried B, Sherma J (2006) Effects of diet on the carotenoid pigment and lipid content of Pomacea bridgessi as determined by quantitative high performance thin layer chromatography. Comp Biochem Physiol B Biochem Mol Biol 143:244-248

Khachik F, Beecher GR, Goli MB, Lusby WR (1991) Separation, identification, and quantification of carotenoids in fruits, vegetables and human plasma by high performance liquid chromatography. Pure Appl Chem 63:71-80

Ligor M, Buszewski B (2007) Thin layer chromatographic techniques (TLC, OPTLC) for determination of biological activated compounds from herb extracts. J Liq Chromatogr Relat Technol 30: $2617-2628$

Marsili R, Callahan D (1993) Comparison of a liquid solvent extraction technique and supercritical fluid extraction for the determination of $\alpha$ - and $\beta$-carotene in vegetables. J Chromatogr Sci 31: $422-428$

Martin DL, Fried B, Sherma J (2005) The absence of betacarotene and the presence of biliverdin in the medicinal leech Hirudo medicinalis as determined by TLC. J Planar Chromatogr $18: 400-402$

Minguez-Mosquera MI, Gandul-Rojas B, Gallardo-Guerrero ML (1992) Rapid method of quantification of chlorophylls and carotenoids in virgin olive oil by high-performance liquid chromatography. J Agric Food Chem 40:60-63 
Minguez-Mosquera MI, Garrido-Fernandez J (1989) Chlorophyll and carotenoid presence in olive fruit (Olea europaea). J Agric Food Chem 37:1-7

Murata T, Tamai H, Morinabu T, Manago M, Takenaka A, Takenaka H, Mino M (1992) Determination of beta-carotene in plasma, blood cells and buccal mucosa by electrochemical detection. Lipids 27:840-843

Murkovic M, Zeb A (2010) Thin-layer chromatographic analysis of carotenoids in plant and animal samples. J Planar Chromatogr 23:94-103

Oliver J, Palou A (2000) Chromatographic determination of carotenoids in foods. J Chromatogr A 881:543-555

Omenn GS, Goodman G, Thornquist M, Grizzle J, Rosenstock L, Barnhart S (1994) The beta-carotene and retinol efficacy trial (CARET) for chemoprevention of lung cancer in high risk populations: smokers and asbestos-exposed workers. Cancer Res 54:2038s-2043s

Paiva SAR, Russell RM (1999) $\beta$-carotene and other carotenoids as antioxidants. J Am Coll Nutr 18:426-433

Palozza P (1998) Prooxidant actions of carotenoids in biologic systems. Nutr Rev 56:257-265

Palozza P, Calviello G, Serini S, Maggiano N, Lanza P, Ranelletti FO, Bartoli GM (2001) $\beta$-carotene at high concentrations induces apoptosis by enhancing oxy-radical production in human adenocarcinoma cells. Free Radic Biol Med 30:1000-1007

Quackenbush FW, Smallidge RL (1986) Reversed phase liquid chromatographic system for separation and quantitation. J Assoc Off Anal Chem 69:767-772
Renger B, Végh Z, Ferenczi-Fodor K (2011) Validation of thin layer and high performance thin layer chromatographic methods. J Chromatogr A 1218:2712-2721

Rodriguez-Bernaldo De Quiros A, Costa HS (2006) Analysis of carotenoids in vegetable and plasma samples: a review. J Food Compos Anal 19:97-111

Schierle J, Schellenberger T, Fizet C, Betz R (2002) A simple spectrophotometric determination of total $\mathrm{b}$-carotene in food additives with varying E/Z-isomer ratios using an isosbestic wavelength. Eur Food Res Technol 215:268-274

Sherma J (2000) Thin-layer chromatography in food and agricultural analysis. J Chromatogr A 880:129-147

Sherma J, Fried B (2004) Separation and determination of chloroplast pigments from spinach by thin-layer chromatography: a student laboratory experiment. J Planar Chromatogr 17:309-313

Taungbodhitham AK, Jones GP, Wahlqvist ML, Briggs DR (1998) Evaluation of extraction method for the analysis of carotenoids in fruits and vegetables. Food Chem 63:577-584

Van Den Berg H, Faulks R, Granado HF, Hirschberg J, Olmedilla B, Sandmann G, Southon S, Stahl W (2000) The potential for the improvement of carotenoid levels in foods and the likely systemic effects. J Sci Food Agric 80:880-912

Ziyatdinova G, Ziganshina E, Budnikov H (2012) Voltammetric determination of $\beta$-carotene in raw vegetables and berries in Triton X 100 media. Talanta 99:1024-1029 